claim that it is a very good design. The airlines which will have to buy it are naturally taking a more cautious line, and can hardly be expected to do more until the specification and costs are more clearly defined. And because the airlines put a high value on their independence, they are reluctant to make encouraging noises too soon.

There is also the possibility that Boeing may decide to enter the competition. Although Boeing has not yet made a definite statement of intention, it has worked on a design with some similarities to the European airbus, and this is enough to make the airlines hedge their bets until the position is clearer. Boeing has a loyal following among the airlines; British European Airways, for example, would have bought Boeing aircraft rather than the Hawker-Siddeley Trident if it had been allowed to. The delay in the airbus project gives Boeing a chance to get into the short-haul airbus market if it decides to. The best hope for the companies in the European airbus would be for Boeing to get so involved in the task of redesigning the American SST that it had no time to contem. plate more mundane aircraft.

Despite the uncertainty, the three firms involved in the European airbus have now formed a new company, to be called Airbus International. The task of the new company, which comprises Hawker Siddeley Aviation, Sud Aviation and Deutsche Airbus, will be to sell the airbus to the airlines, and to coordinate the activities of the three companies. Shares in the company have been taken up in proportion to the share of the cost of the project-37.5 per cent for France and Britain, and 25 per cent for West Germany. The chairman of the company is Dr Bernhardt Weinhardt, of Deutsche Airbus.

\section{Why Britain Withdrew}

Mr Edward SHort, the Secretary of State for Education and Science, is clearly not a man to shirk unpleasant duties. Last week he appeared before the Council for Scientific Policy to explain why the British Government had declined to accept its advice on the CERN $300 \mathrm{GeV}$ accelerator. Mr Short said that the Government had decided that it could not afford any new commitment. If the Government had signed the agreement, he said, it would not have been able to withdraw later, and the cost of the machine would probably increase. It felt that there were no short or medium term prospects of economic benefits from so costly a scheme and little chance of movement into industry of skilled manpower trained by participation in international high energy physies projects.

The Government had rejected the SRC proposal that the proportion of resources allocated to nuclear physics could be reduced by closing down obsolete national facilities and spending part of the money on the $300 \mathrm{GeV}$ machine, on the grounds that unless the CERN machine was built in Britain there would be no adequate facilities to train British scientists. Mr Short also said that this plan of the council assumed a substantial growth of the SRC budget over the next decade and the Government was not prepared to commit itself or its successor so far ahead. The minister assured the meeting that the decision was not the thin end of the wedge of Government interference in the disposal of the Research Council's funds and, presum- ably as a word of encouragement to the countries left in the scheme, he said the decision was not an attempt to discourage the project.

\section{Nuclear Estimates}

The European Nuclear Energy Agency has just made a courageous attempt to estimate the growth of nuclear power in Western Europe, and how different mixtures of reactors will affect the demand for uranium and for enrichment facilities. The attempt is courageous because estimates of this sort are notoriously tricky to do, and always likely to be overtaken by technical developments of one sort or another. The report, Illustrative Power Reactor Programmes (ENEA), covers itself by allowing generous margins for error-its low nuclear demand forecast for the year 2000 is less than half its high demand forecast-but the effort is nevertheless worthwhile.

By 1980 , the report estimates, the amount of electricity generated by nuclear power in Europe will have risen to $110 \mathrm{GW}\left(10^{9}\right.$ watts), from $10 \mathrm{GW}$ in 1970 and 40 GW in 1975 . Estimates after that are clearly more dubious, but the report suggests a demand of $392 \mathrm{GW}$ in $1990,800 \mathrm{GW}$ in 2000 and $1,350 \mathrm{GW}$ in 2010 . There are many ways in which this electricity could be generated, and the report considers some of

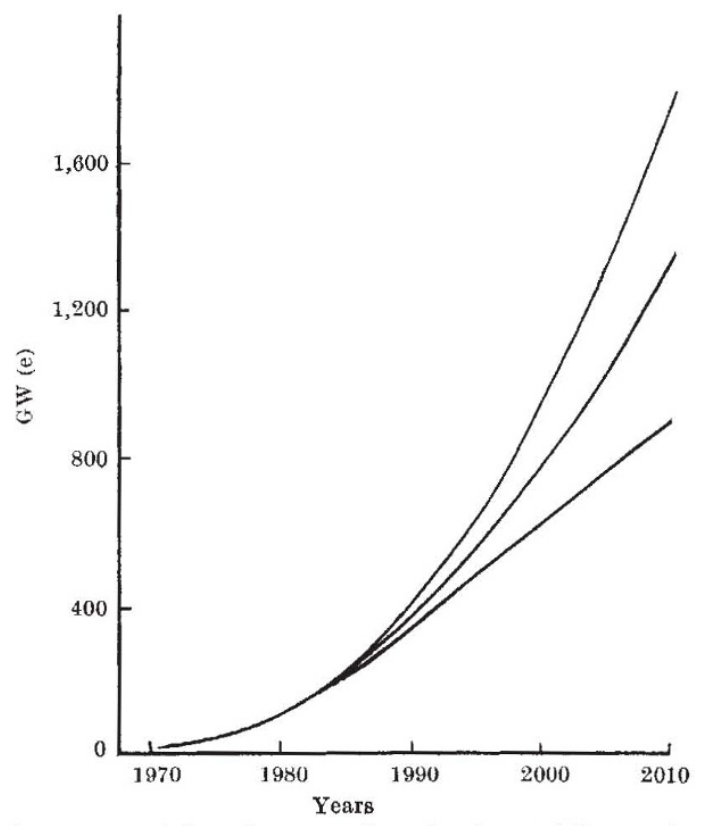

High, mean and low forecasts for the demand for nuclear power in Western Europe, 1970-2010. (OECD.)

the possible combinations of reactor types. The introduction of advanced thermal converters and fast breeders, certain to happen over the period under consideration, would be particularly important because of the effect it could be expected to have on uranium requirements. A nuclear power programme involving light water reactors only, for example, would by the year 2000 have used up nearly 2 million metric tons of uranium, and would be using it at an annual rate of 150,000 metric tons a year. A mixed system using light water reactors and fast breeders, on the other hand, would reduce the annual uranium requirements 
to less than 100,000 metric tons per year, even at the highest forecasts of nuclear demand.

Different nuclear programmes would also affect the need for fuel enrichment facilities, and this is perhaps the most crucial issue raised by the report. A system using a mixture of light water reactors and fast breeders would show a steadily increasing need for enrichment facilities up to and beyond 2010. But if the system also included some fast converters, the demand for enrichment facilities would tail off by 1990 , and might show a small decline after that. If more pessimistic assumptions about the rate of growth of power demand are assumed, the need for enrichment facilities might actually decline quite sharply after 1990. This kind of argument can serve two purposes; first it can help to determine whether investment in enrichment is justified, and second it can show that, by carefully relating the systems chosen to the growth of demand, maximum use can be made of existing plant.

In fact, decisions about nuclear power plant are rarely made for such esoteric reasons. It is usually the generating costs which decide. But, although the survey is in this sense of academic interest, it reflects the kind of thinking which will increasingly have to be done, both by governments and utilities.

\section{Read Fewer Journals}

Two reports published recently confirm that a good coverage of a particular scientific subject can be obtained by reading a relatively small number of journals. One of the reports (Investigation on Nuclear "Core Journals", by E. Böhm, EUR 3887 e; 1968) is of a survey in the field of nuclear scienco and technology conducted by the Centre for Information and Documentation, run by Euratom in Brussels. The survey was based on articles abstracted by Nuclear Science Abstracts and by seventeen other abstracting and indexing services. The results show that 272 "core journals" (13.8 per cent) out of a total of 1,978 different primary periodicals produce about 75 per cent of the relevant articles in the nuclear field. Of these "core journals", nearly three-quarters ( $73 \cdot 3$ per cent) came from the United States, Canada and Western Europe; 22.2 per cent from the Soviet Union and Eastern Europe; and the remainder (4.7 per cent) from other countries. The top journal was the Bulletin of the American Physical Society with 961 citations in the abstracting journals. This was followed by The Physical Review (504 citations), Transactions of the American Nuclear Society (378 citations) and Physics Letters (288 citations). Nature, the first British journal in the list, came seventh in the list with 223 citations.

Another recent post-mortem on journal literature, this time in the wider field of physics, has been published by the American Institute of Physics (Journal Literature Covered by Physics Abstracts in 1965, by $\mathrm{S}$. Keenan and F. G. Brickwedde, $I D$ 68-1; 1968). It is a sequel to a similar report published in 1961. Some information from the earlier survey is included in this latest report to show the pattern of development of physics literature over the five-year period.

The results are interesting though not, perhaps, surprising. Compared with the 1961 figures the number of journal articles in 1965 increased by 60 per cent (a total of 32,279 articles from 495 journals were collected). The number of journals abstracted in 1965 , however, only increased by $22 \cdot 2$ per cent. This shows that the growth of Physics Abstracts has been caused by the increasing number of scientific papers in the most productive primary journals over the past five years. These journals are published by the prineipal contributing countries - the United States ranks first with the highest number of abstracts, and the largest number of journals (93); Britain ranks third behind the Soviet Union in the number of abstracts, but it is second in the number of journals abstracted (92). The report notes the substantial increase in the number of papers published in the Netherlands-probably explained by the publication there of several productive "international" journals. A point the report makes, but does not attempt to explain, is the increase in the number of Japanese journals covered by Physics Abstracts between 1961 and 1965, but without a corresponding increase in the number of abstracts - there was in fact a decline.

The pattern that a few journals generate a high proportion of the total number of papers is found in physics as in nuclear science and technology and other subjects. In Physics Abstracts 1965, 75 per cent of the abstracts were generated by 60 journals or only $12 \cdot 1$ per eent of the number of journals (495) abstracted. In the ranked list, The Physical Review comes first, followed by Journal of Chemical Physics and Physics Letters. Nature again heads the British journals, coming sixteenth in the league table.

\section{Cheerful Aslib}

THE present financial climate certainly does not yet seem to have affected the fortunes of Aslib. Indeed, the impression given from its annual report for 1967 is that the association is flourishing, with its gross income reaching a record level of $£ 137,002$, an increase of 10 per cent over 1966. Members' subscriptions rose and, with extended financial support from the Office for Scientific and Technical Information (OSTI), research activities were expanded. Expenditure on research and consultancy during the year rose from $£ 21,618$ to $£ 37,808,65$ per cent of this being covered by grant and special project funds from OSTI.

The research department, with a staff of eighteen, brought four projects almost to completion during 1967 - on the literature of plasma physics, the identification and ranking of UK journals carrying original scientific work, surveys of the use of technical libraries, and the use of social science literature; and six new projects were begun. Two of these new projects involve surveys of the forms and uses of bibliographic records in British libraries, and information services in metallurgy. 'The first of these two surveys will give valuable background information for the planning of the availability of bibliographical data in a form that can be read by machines.

Now that the Government is becoming better aware of the importance of information services in the economy, it is natural that Aslib should have been asked by the Government to assist the Dainton Committee in its deliberations over the functions and organization of a national library system. The comments of Aslib on the points raised by the Dainton Committee and on other matters relating to the requirements of a national library are published in Aslib Proceedings, 20 (7); 1968.

In principle, Aslib's recommendations are similar 